\section{EMBRYRIDDLE}

Aeronautical University

SCHOLARLY COMMONS
Journal of Aviation/Aerospace

Education \& Research

Volume 24

Number 1 JAAER Fall 2014

Article 1

2014

\title{
Correlates of Continued Visual Flight Rules (VFR) into Instrument Meteorological Conditions (IMC) General Aviation Accidents
}

David Ison

isond46@erau.edu

Follow this and additional works at: https://commons.erau.edu/jaaer

\section{Scholarly Commons Citation}

Ison, D. (2014). Correlates of Continued Visual Flight Rules (VFR) into Instrument Meteorological Conditions (IMC) General Aviation Accidents. Journal of Aviation/Aerospace Education \& Research, 24(1). https://doi.org/10.15394/jaaer.2014.1628

This Article is brought to you for free and open access by the Journals at Scholarly Commons. It has been accepted for inclusion in Journal of Aviation/Aerospace Education \& Research by an authorized administrator of Scholarly Commons. For more information, please contact commons@erau.edu. 


\section{INTRODUCTION}

\section{Overview of the Study}

Each year, millions of dollars and many lives are lost in general aviation accidents (Landsberg, 2004). Between 2001 and 2011, there was an annual average of 1,760 accidents which resulted in an average of 333 fatalities (National Transportation Safety Board [NTSB], 2013a). According to the 2011 Aircraft Owners and Pilots Association (AOPA) Nall Report, $3.7 \%$ of accidents in 2010 were weather related yet these accidents accounted for $27.1 \%$ of fatalities. The average resultant lethality of weather related accidents was $63 \%$ which was the highest among all types of general aviation accidents (AOPA, 2011). Of these weather related accidents, $48.8 \%$ involved attempts to continue VFR flight into instrument meteorological conditions (IMC). (AOPA, 2011). Among these particular accidents, 51.2\% were fatal (AOPA, 2011). Pearson (2002) noted that even in light of improvements in aviation safety, "attempted VFR flight into Instrument Meteorological Conditions (IMC) were the most frequently cited cause or factor in weather-involved fatal general aviation accidents" (p. 1). Goh and Wiegmann (2001) stated that in light of the aforementioned statistics, VFR flight into IMC accidents are "a major safety hazard within general aviation" (p. 1).

Numerous studies have been conducted on the causal factors of general aviation accidents. Each year, the AOPA (2011) releases an extensive study on general aviation accidents. Li, Baker, Grabowski, and Rebok (2001) investigated the pilot error factors involved in aviation crashes at the general aviation, commuter air carrier, and major air carrier levels. Government agencies in the United States and in other countries release comprehensive reports on accident statistics and the causes of such accidents (Federal Aviation Administration, 2010; Goh \& 
Wiegmann, 2001; Transport Canada, 2011). Studies have also been completed on the potential correlates associated with aviation accidents. Commonly investigated characteristics have included pilot age, gender, medical certificate class, pilot certificate level, flight experience, time of day, type of aircraft, and basic weather conditions (Li, Baker, Lamb, Qiang, and McCarthy, 2005; Li, Baker, Grabowski, Qiang, and Rebok, 2002; Li, et al., 2001; Goh and Wiegmann, 2001; Wiegmann, Goh, and O'Hare, 2002). Research has also been conducted specifically on continued VFR into IMC accidents (Coyne, 2004; Detwiler, Holcomb, Hackworth, and Shappell, 2008; Goh and Wiegmann, 2001; Wiegmann, et al., 2002; Pearson, 2002). While these studies have investigated human factors issues associated with these accidents such as pilot judgment, situation assessment, and experience, the literature has essentially ignored correlative characteristics of continued VFR into IMC accidents. Only two studies have addressed these factors to determine if there were in fact and relationships among the data. One study provided no statistical analysis while the other only provided an analysis of two factors (Detwiler, et al., 2008; Goh and Wiegmann, 2001). Clearly, a more thorough examination of the characteristics of this type of accident is necessary to best understand the phenomenon.

\section{Purpose of the Study}

The purpose of this study was to identify pilot and situational characteristics that have correlations to continued VFR flight into IMC general aviation accidents. Further, this study sought to compare these characteristics in continued VFR flight into IMC accidents to other types of general aviation accidents. 


\section{Research Objectives and Research Questions}

This study was guided by the following research questions:

1. What are the characteristics of pilots who were involved in fatal continued VFR flight into IMC general aviation accidents? Specifically, how are pilot certification, age of the pilot, flight time, and receipt of a weather briefing related to occurrence of these accidents?

2. What are the situational characteristics of fatal continued VFR flight into IMC general aviation accidents? Specifically, how were the time of accident, the type of terrain at the crash site, if a flight plan was filed, and if the flight was in contact with air traffic control (ATC) at the time of the crash related to the type of accident?

3. Are there differences in pilot and situational characteristics in continued VFR flight into IMC general aviation accidents as compared to those in other types of general aviation accidents?

\section{Significance of the Study}

This study seeks to enhance knowledge of the features of continued VFR flight into IMC general aviation accidents. This data should assist in the education of pilots on the risk factors associated with these accidents. Further, stakeholders in aviation consistently desire to gain an improved understanding of aircraft accidents, their causes, and factors related to their incidence. The data from this study will be able to augment this understanding. 


\section{REVIEW OF LITERATURE}

\section{Aviation Accidents}

Within the United States, the NTSB is the government body that is responsible for the investigation of accidents involving aircraft. The NTSB defines an accident as "an occurrence associated with the operation of an aircraft that takes place between the time any person boards the aircraft with the intention of flight and all such persons have disembarked, and in which any person suffers death or serious injury, or in which the aircraft receives substantial damage" (NTSB, n.d., para. 1). Accident investigations conducted by the NTSB are documented in a highly-standardized format. Records of these investigations, accident reports, and accident statistics are then made available to the public through the NTSB website (NTSB, 2013a). The FAA also participates in the accident and incident investigation process, but defers to the NTSB for publication of final reports and for the majority of event statistical reporting and analysis (FAA, 2010).

\section{Aviation Accident Statistics}

Between 2001 and 2011, there was an annual average of 1,760 accidents which resulted in an average of 333 fatalities (AOPA, 2011; NTSB, 2013a). In 2011 alone, there were 1,466 accidents of which 263 involved fatalities. The total number of deaths associated with these incidences, including those killed on the ground, was 444 (NTSB, 2013a). These accidents have a tremendous impact on public confidence in air transportation and clearly have serious consequences in terms of costs, both human and fiscal (Wiegmann and Shappell, 2003). 


\section{Research Associated with Aviation Accidents}

Because of the high visibility and the significant costs of aviation accidents as well as the critical nature of aviation to the U.S. transportation infrastructure, there has been an immense interest in aviation accidents and their causes (Air Transport Association, 2009; AOPA, 2008). The NTSB invests a significant amount of manpower and money to thoroughly explore all aspects associated with an aircraft accident (NTSB, 2002). The resulting reports include the input of experts in a wide range of subject areas including aircraft manufacturing, engines, human factors, language, piloting, air traffic control, and engineering (Krause, 2003).

Within the academic community, a large body of more in depth research has been conducted. Much of this research has been on human factor influences on accidents. This should be of no surprise since human factors were indicated as the cause of over $80 \%$ of aviation accidents (FAA, 2008). Both Roscoe (1980) and Garland, Wise, and Hopkin (1999) provided a broad overview of a variety of human factor issues associated with aviation. Pilot performance was investigated to see what the limits of in-flight workload and the necessary coping strategies to handle such stresses. Fatigue issues were also outlined to describe how the body reacts to prolonged periods of consciousness and how these conditions can negatively influence flight safety. Even among aircraft incidents (an event involving safety of flight issues but not as serious as an accident), human factors are involved in over $80 \%$ of occurrences (Billings and Reynard, 1984). Further, Billings and Reynard (1984) discovered that the majority of accidents and incidents were deemed to be preventable with interventions to such human errors.

The positive interaction of multiple pilots and crew members has been shown to promote flight safety (Wiener, Kanki, and Helmreich, 1993; Wise, et al., 1999). This concept of 
teamwork, typically referred to as crew resource management (CRM), is one of the more highly investigated areas in aviation human factors (Helmreich, 1995; Merritt and Helmreich, 1995; Salas, Fowlkes, Stout, Milanovich, and Prince, 1999; Weiner, et al., 1993; et al., 1999). O’Hare and Roscoe (1990) explored the influences of social psychology on the safety of flight operations. Again, concerted efforts at handling the interaction of stakeholders were indicated to improve group-think, situational awareness, and overall performance safety.

Additional research has been conducted on correlates embedded in accident reports and statistics. Hunter (2001) noted that an abundance of research has been conducted relating "pilot biodata, personality measures, and accident involvement" (p. 509). Characteristics commonly examined were identified as age, gender, education, flying experience, and prior accidents (Hunter, 2001). Li, et al. (2001) investigated potential ties between pilot error and pilot characteristics. The attributes examined included pilot gender, flight time, level of certification, time of the accident, location of the accident, weather conditions, type of aircraft, and lethality of the occurrence. Substantial findings included similar rates of human error in accidents involving major and commuter airline pilots. Further, the incidence of pilot error accidents was stable among these groups of pilots even as total hours of flight experience increased. Human error was also more likely to have caused airline accidents that occurred at an airport and in poor weather. There was no statistical significance of time of day of airline accidents (Li, et al., 2001).

$\mathrm{Li}$, et al. (2002) specifically targeted the relationship of age and experience to accident prevalence involving pilot error among a group of professional pilots. The premise of this study was that older individuals have degraded memory and motor skills, therefore it was expected that older pilots would have higher chances of being involved in an accident. The prevalence of pilot error in accidents among major airline pilots declined from age 30 to age 39 , reached the lowest 
incidence at ages 40 to 49 , but then rose slightly among pilots aged 50 to 59. Among commuter/air taxi pilots, the number of accidents rose from age 20 to 39, remained stable from age 40 to 49 then rose steadily from age 50 upwards. There were no statistically significant differences identified in the prevalence of accidents involving pilot error in relationship to hours of flight experience among major and commuter/air taxi pilots. However, there was a slightly higher pilot error rate among major airline pilots with low flight time (Li, et al., 2003).

\section{General Aviation Accidents and Statistics}

While airline operations tend to get much of the limelight from media when accidents occur, accidents involving general aviation operations (e.g. private, corporate, aerial application, and instructional flights) are much more prevalent (AOPA, 2009). In 2011, there were 1,466 general aviation accidents while there were only 31 accidents involving CFR part 121 and part 135 air carriers. This is particularly alarming considering that general aviation accumulated approximately 22.5 million flight hours during 2011 in comparison to 17.7 million flight hours accumulated by CFR part 121 and part 135 air carriers. Statistically, a general aviation flight is 70 times more likely to be involved in an accident than a scheduled CFR part 121 operation (NTSB, 2013a). Even in light of significant safety improvements over the past 10 years among aircraft and associated technology, accident rates within general aviation have remained relatively stable (AOPA, 2011; Pearson, 2002).

\section{Research Associated with General Aviation Accidents}

The high rate of accident occurrence within general aviation has attracted much attention from researchers. Each year AOPA (2011) publishes a comprehensive analysis of general aviation accident statistics. From 1998 to 2007, the most common causes of general aviation 
accidents, in descending order of prevalence, were pilot-related, mechanical, and unknown. AOPA (2011) examined a variety of pilot characteristics in order to identify potential relationships with accident incidence. Individuals with less than 500 hours of flight experience were involved in nearly half of general aviation accidents. However, as AOPA (2008) noted, because these pilots are also the most numerous in general aviation, statistical data did not indicate that low flight time equated with increased accident risk. The study did state, however, that "it's not clear whether lower-time pilots were less exposed to the risk of accidents because they did less flying" (p. 9). In the other extreme, high time pilots (more than 20,000 hours) were involved in "three and a half times as larger share of accident [s ...], though this may also reflect factors such as age or lack of recent light-aircraft experience" (p. 9).

Perhaps a better indication of accident incidence, the level of pilot certificate, was offered by AOPA (2011). Although private pilot certificate holders made up $37.9 \%$ of pilots, they were involved in $49.1 \%$ of accidents. There were $20.7 \%$ of pilots holding commercial certificates and these individuals were involved in $28.2 \%$ of accidents. Airline Transport Pilot (ATP) holders represented $25.9 \%$ of all pilots and were involved in $13.7 \%$ of accidents. The lowest level of pilot certification, the student, represented $15.1 \%$ of certificate holders but was involved in only $5.7 \%$ of accidents. Although no statistical analysis was offered, it was evident that private and commercial pilots had accident incidences higher than their share of the pilot population while the opposite was true among ATP and student certificate holders.

$\mathrm{Li}$, et al. (2001) identified factors associated with accident rates among general aviation pilots. Three pilot attributes, age, flight time, and certificate level were noted to be statistically significant. "Of the general aviation crashes involving pilots under age 20, 94\% were attributed to pilot errors, compared with about $85 \%$ of general aviation crashes involving older pilots" (Li, 
et al., 2001, p. 54). Pilot error rates declined slightly among pilots age 20-29 to those over the age of 60 . Pilot error rates dropped from $91 \%$ among low-time pilots to $79 \%$ among pilots with the most flight time. Also, "general aviation crashes involving student/private pilots were more likely to be attributed to pilot error than other general aviation crashes" (Li, et al., p. 54).

Other correlates of general aviation accidents were investigated by $\mathrm{Li}$, et al. (2005). In this study, the incidence of alcohol-related accidents was compared to those not involving alcohol. In this study, characteristics of pilots in alcohol-related crashes were collected and examined for statistical significance. These included age, gender, medical certification level, principal profession, pilot certification level, flight time, recent of flight experience, type of airplane, month of the crash, day of the crash, time of the crash, and basic weather conditions. Only three of these items were identified to have significant correlation to the occurrence of the accident. Significantly more accidents occurred among pilots with a third class medical certificate than those with higher certification $(p=0.02)$. Most accidents occurred during the period of April through June $(p=0.10)$. Lastly, the majority of alcohol-related accidents occurred at night versus the majority of non-alcohol related accidents occurred during the day ( $p$ $=0.01)(\mathrm{Li}$, et al., 2005).

\section{Weather Related Accidents and Statistics}

AOPA (2011) categorized general aviation accidents into types or descriptive sub-sets based upon causes or factors associated therein. The highest percentage $(73.9 \%)$ of accidents occurred as a result of pilot-related issues, with a 5\% of fatal accidents being attributed to pilotrelated weather issues. AOPA (2011) stated that the average lethality rate of weather accidents was $63 \%$, which was high among accident categories. These statistics are alarming because only 
$3.7 \%$ of all general aviation accidents are caused in some form by weather. Considering that "weather affects piloting more than any other physical factor" (Coyne, 2004, p. 1) it is unrealistic to believe that weather, as a challenge to flight operations, can be eliminated. Even more disturbing is that fact that "despite its importance for flight safety, many pilots believe weather is the most difficult and least understood subject in their pilot training" (Coyne, 2004, p. 1).

Not surprisingly, the relationship of weather to accident incidence has been a highly investigated subject. AOPA (2011) stated that most accidents occurred during the day in good (Visual Meteorological Conditions [VMC]) weather. This is most likely due to the fact that most operations occur during these conditions. In terms of fatalities, while most occurred during day VMC, there was a much higher chance of death for flights conducted at night and in poor weather (Instrument Meteorological Conditions [IMC]). During day VMC, only $21.4 \%$ of accidents were fatal while accidents that occurred in night VMC $3.6 \%$ were fatal. When accidents occurred in day IMC, $66.7 \%$ were fatal and among those occurring in night IMC, $77.8 \%$ were fatal (AOPA, 2011).

\section{Continued VFR into IMC Accidents and Statistics}

It is somewhat understandable if a pilot is somehow caught off-guard by some unforecast or unforeseen weather phenomenon, but research indicates that it is quite common that pilots knowingly enter bad weather and/or use poor decision making when facing deteriorating conditions. This type of occurrence is commonly referred to continued VFR flight into IMC. The cause of such occurrences is "often found to be a willful disregard for the regulations and cues that dictated an alternative and safer course of action" (Wiegmann, et al., 2002, p. 190). AOPA (2011) reinforced these findings by stating "most often, these fatal accidents resulted from pilots 
deciding to continue VFR flight into instrument meteorological conditions (IMC)" (p. 6). Unfortunately, pilots who are not prepared or qualified to fly in adverse weather conditions quickly become overwhelmed and "upon entering IMC, pilots typically become disoriented" (Coyne, 2004, p. 4). This typically results in loss of control and the resultant crashes are normally not survivable. In fact, "72\% of [...] VFR flight into IMC accidents were fatal, compared to an overall [general aviation] accident rate of 17\%" (Goh and Wiegmann, 2001, p. $1)$.

\section{Research Associated with Continued VFR into IMC Accidents}

Because of the high fatality rates and the association of this type of accident to pilot error, there have been several studies that have been conducted on the factors associated with continued VFR into IMC accidents. Wiegmann, et al. (2002) investigated the potential for a relationship between situation assessment and flight experience in a pilot's decision to continue VFR into IMC. This study discovered two relationships within the collected data. First, it was found that the earlier in the flight that adverse weather was encountered, the more likely pilots were to continue their itinerary. Second, pilots with higher levels of flight experience were more likely to divert away from the adverse conditions earlier in the flight than pilots of lower experience levels.

Goh and Wiegmann (2001) sought correlates within continued VFR into IMC accidents by comparing these accidents with all general aviation accidents. The study only provided two correlations. The first was an indication that the median number of flight hours of pilots in VFR into IMC accidents was lower than all other types of general aviation accidents $(p<0.01)$. The second finding was that there was a higher occurrence of continued VFR into IMC accidents 
among pilots at or below the private pilot certification level in comparison to those at higher certification levels $(p<0.01)$.

Detwiler, et al. (2008) also investigated potential correlates in continued VFR into IMC accidents by comparing them to the incidence of other general aviation accidents. Supporting their call for the identification of possible relationships within accident data, this study stated that:

no single explanation seems to account for all VFR flight into IMC accidents. Just as experience, as defined by simple flight hours, cannot explain all VFR flight into IMC; neither can motivational factors, poor situational awareness, lack of knowledge, or poor pilot decision-making alone account for these accidents. Rather it is probably a combination of all these issues, and perhaps more, that contribute to what accident investigators refer to as VFR flight into IMC (Detwiler, et al., 2008, p. 1).

This study identifies a multiplicity of potential correlates of continued VFR flight into IMC accidents such as pilot demographics, environmental factors, aircraft types, and pilot flight experience. Unfortunately, no statistical significance was offered as to the relationship of these factors to the incidence of continued VFR flight into IMC. Further, no evidence was indicated as to the existence of any possible relationship of these factors between continued VFR flight into IMC accidents and other types of general aviation accidents.

The predominance of fatalities among continued VFR flight into IMC as well as the lack of research that exists on factors associated with these incidences beckons further investigation. As Li, et al. (2001) noted, the cause of an accident "is a function of both endogenous and exogenous factors. $[\ldots]$ extrinsic attributes $[\ldots]$ are important determinants [in accidents] as well" (p. 52). Thus traditional examinations of accidents must be further expanded to look into additional possible influences. Also, as Detwiler, et al. (2008) recognized, it is incomplete to simply investigate the human element alone when seeking what may have played a role in an 
accident. Lastly, the negative human and fiscal costs associated with these accidents cannot be undervalued. All of these factors coupled together demand further investigation of the features of continued VFR flight into IMC accidents and the interrelationship of such intricacies.

\section{METHOD}

This study utilized analytical methods to determine correlations and predictors of fatal continued VFR into IMC accidents. These accidents were compared vis-à-vis with fatal accidents unrelated to continued flight into IMC. As identified in the exigent research, numerous factors have been identified as to potentially be factors in VFR into IMC accidents. From the guidance of these studies, the following items were selected for this study:

- Terrain - whether the accident occurred in mountainous/elevated terrain or in areas without such features

- Time of day - whether the accident occurred during the day or at night

- Weather briefing - whether the pilot received a weather briefing or not

- Flight plan - whether the pilot filed a flight plan or not

- Age - age of the pilot in command

- Hours - total pilot flight experience in hours of the pilot in command

- Certificate - pilot in command certification level categorized as student, private/recreational/sport, commercial, or Airline Transport Pilot (ATP)

- Air traffic control (ATC) - whether or not the pilot was in contact with ATC at the time of the crash

Due to the dichotomous nature of the dependent variable - crash type (VFR into IMC versus non-VFR into IMC) - logistic regression was utilized to determine the relationships between the 
aforementioned independent variables and the crash type. Further investigation was conducted using partial correlations controlling for variables identified as significant within the logistic regression model in an attempt to closer examine the remaining variables as recommended by Pallant (2007).

\section{Subject Characteristics and Sampling}

Fatal general aviation aircraft accident reports were collected from the NTSB accident database. The initial search was conducted using the term "VFR into IMC." Accident reports were reviewed to insure they provided all necessary data on the independent variables. Those that were missing data were excluded. Forty accident reports were selected from these search results. Next, fatal aircraft accident reports were collected and examined to insure they were not related to VFR into IMC. Again, reports were examined to insure they had all relevant factors. Forty accident reports were selected from the results. Fatal aircraft accident reports were randomly selected from the search results. Within these, some reports did not include all of the variables being investigated in this study. These reports were excluded. A total of 80 accident reports were analyzed.

\section{Sample Size/Power/Precision}

According to Agresti (2007), logistic regression should have 10 cases per variable. This would result in required sample size of 80 . This was achieved even in light of the selection criteria and the fact that many accident reports did not include the required variables. The logistic regression calculation met all other assumptions for the test including tests for multicollinearity and the identification of outliers. The correlation calculations achieved a power slightly less than 0.80. The sample was evaluated for level of measurement, related pairs, independence, 
normality, linearity, and homoscedacity to confirm the assumptions for the partial correlation were met (Pallant, 2007).

\section{Measures}

Data was collected from the NTSB database which is considered to be a reliable source created and managed by a government entity. The individuals that investigate and write these reports are highly qualified and considered to be subject matter experts (NTSB, 2013b).

\section{Research Design}

The accident reports were coded per the dependent and independent variables. These were entered in an Excel database after being examined for the requisite variables. Once the data collection process was complete, the Excel data was exported to SPSS for analysis. Logistic regression was conducted on the resultant file. Upon identifying variables that had a significant effect on the model, partial correlations were conducted controlling for these items to further investigate the strength of effects of other the remaining variables.

\section{RESULTS}

Direct binary logistic regression was performed to assess the impact of factors identified in the research literature may have on the accident type in terms of VFR into IMC versus those unrelated to weather. The model contained eight independent variables (time of day [day or night], terrain [mountainous/elevated or flat], weather briefing [received or none], flight plan [filed or not filed], air traffic control [within contact at time of crash or not in contact], pilot certificate level [student, private/recreational/sport, commercial, ATP], total pilot hours, and pilot age). The regression model containing all independent variables was found to be 
statistically significant, $\chi^{2}(8, N=80)=35.88, p<0.001$ indicating that the model was able to identify accident type via the associated factors. The model was able to classify $36.1 \%$ (Cox and Snell R square) and 48.2\% (Nagelkerke R square) of the variance in accident type. The model was able to correctly classify $76.3 \%$ of cases which was a substantial improvement over the initial SPSS calculation of 50\%. As shown in table one, only two independent variables (terrain: mountainous/elevated and weather briefing: received) significantly contributed to the model. The strongest predictor was the weather briefing which provided an odds ratio (Exp[B]) of 19.097. This indicated that those involved in a fatal continued VFR flight into IMC were 19 times more likely to have received a weather briefing, controlling for other factors. Terrain also had a high odds ratio, indicating that VFR into IMC accidents were 10 times more likely to involve mountainous/elevated terrain.

Additional support for the model was indicated by the Hosmer and Lemeshow test $\chi^{2}(8$, $N=80)=7.856, p=0.45$. For this test, results of $p>0.05$ indicate a good model fit (Pallant, 2007). The positive predictive value of the model was $72 \%$ and the negative predictive value was calculated to be $82 \%$. Residuals were analyzed and only one case was found to exceed the value of 2.5 explicated by Pallant (2007). This case was confirmed to be properly entered into the database. Because there was only this one outlier, no modification to the model was made.

Correlation matrices were generated by the model calculation. Several combinations indicated noteworthy correlation values albeit significance was not provided by SPSS. The higher the certification level, the lower the likelihood of a continued VFR into IMC accident, $r=$ -.641. As pilot total flight time increased, the higher the likelihood of this type of accident, $r=$ .535. For older pilots, there was a lower likelihood of analogous accidents, $r=-.722$. 
Table 1

Logistic regression predicting likelihood of accident type

Variables in the Equation

\begin{tabular}{|ll|r|r|r|r|r|r|}
\hline & & & & & & \\
& & \multicolumn{1}{c|}{ B } & \multicolumn{1}{c|}{ S.E. } & Wald & df & \multicolumn{1}{c|}{ Sig. } & Exp(B) \\
\hline Step 1 & Time_of_day(1) & .678 & .747 & .824 & 1 & .364 & 1.970 \\
& Terrain(1) & 2.324 & .650 & 12.786 & 1 & .000 & 10.219 \\
& WX_Brief(1) & 2.950 & .919 & 10.303 & 1 & .001 & 19.097 \\
& Flt_Plan(1) & -.553 & 1.028 & .289 & 1 & .591 & .575 \\
ATC(1) & .484 & .698 & .481 & 1 & .488 & 1.623 \\
Cert & -.366 & .508 & .520 & 1 & .471 & .693 \\
Hours & .000 & .000 & .723 & 1 & .395 & 1.000 \\
Age & -.019 & .022 & .698 & 1 & .403 & .982 \\
Constant & -.291 & 1.696 & .030 & 1 & .864 & .747 \\
\hline
\end{tabular}

Partial correlations were then calculated to control for terrain and weather briefings, as they were noted to be significant in the model, to ascertain potential other relationships. When controlling for terrain, several significant correlations were identified. One was the relationship between accident type and weather briefing, $r=.435, N=80, p<0.005$. If an accident was classified as VFR into IMC, it was more likely that the pilot received a weather briefing. Pilots were more likely to file a flight plan if they also received a weather briefing, $r=.501, N=80, p$ $<0.005$. Also, pilots were more likely to be communicating with ATC if they were on a flight plan, $r=.301, N=80, p<0.01$. When controlling for weather briefing, pilots were more likely to fly VFR into IMC in mountainous areas, $r=.469, N=80, p<0.005$, and pilots were less likely to be on a flight plan when flying in mountainous areas, $r=-.247, N=80, p<0.05$. There was a higher likelihood of an accident in mountainous areas as flight time increased, $r=.266, N$ $=80, p<0.05$. 


\section{DISCUSSION}

As noted earlier in this study, each year there are a substantial number of aviation accidents related to weather, most of which were fatal. Among VFR into IMC accidents, the fatality rate was much higher than in other types of events. With the life and hull losses associated with such accidents, their costs to the aviation community are considerable. Numerous studies have been conducted on aviation accidents from general aviation to the airlines. Within the body of general aviation accident literature, only a few touch on the VFR into IMC topic. Even fewer have investigated causes or potential factors that influence the occurrence of such incidents. This study sought to investigate pilot and situational factors that may be related to continued VFR into IMC fatal events. Through logistic regression and partial correlation analyses, several factors were determined to be good predictors or have relationships with the type of accident.

The results of this study indicate that the model, based upon the selected independent variables, was a good fit for determining the type of accident in terms of whether or not such events were classified as continued VFR into IMC. The model proved to correctly identify accident type in $76.2 \%$ of cases as calculated by SPSS. This advocates for the previous research on prospective correlated of these types of accidents. However, the relationships that the independent variables had with the dependent variable were, in some cases, opposite to intuitive suspicion.

The two significant factors were found to be terrain and weather briefing. It does not seem surprising that pilots may be more compromised when operating in the areas of mountainous or elevated terrain. Such areas often have poor weather which can hide the terrain. 
This, of course, makes erroneous entry into IMC potentially more deadly. Moreover exposure to poor weather is seemingly more likely in such regions. Pilots also may be more used to flying in marginal conditions in these areas which may cause them to "push the limits" in order to complete the flight. Also, as noted is several reports, the opposite was true, with pilots not being used to flying into mountainous areas then encountering weather and subsequently crashing, perhaps due to their unfamiliarity with the rapid changing conditions that can occur around higher terrain. The other significant factor, weather briefing, provided a conclusion divergent from what might be assumed in cases of weather related accidents. Instead of there being a higher incidence of pilots neglecting to gain weather briefings in VFR into IMC accidents, the opposite was true. Thus pilots who lost their lives in these types of accidents were likely made away of the potential for poor weather along their route of flight. This may be explainable by the observation by Wiegmann, et al. (2002) that pilots often show "willful disregard for the regulations and cues that dictated an alternative and safer course of action" (p. 190). This could perhaps also support the notion that pilots who are familiar with flying in areas with poor weather may become accustomed to reports of bad conditions and press on anyway. Clearly, more research must be done to further determine these human factor related issues.

Time of day indicated a small, negative correlation $(r=-.127)$ which indicated a slightly more likelihood that VFR into IMC would occur at night. This seems intuitive as it may be harder for pilots to judge their clearance of terrain and weather in nighttime conditions. This also indicates that many non-VFR into IMC accidents occur during daylight hours, a common time for flight training flights, which have a high incidence of accidents. Flight plans were not a significant determinant of accident type but they did show a very weak negative correlation with the dependent variable ( $r=-.0 .038)$, meaning it was more likely that a VFR into IMC accident 
pilot would not file a flight plan. Perhaps incomplete or poor flight planning can be associated with the probability of encountering bad weather, however there was also a negative correlation $(r=-.550)$ between flight plan and weather briefing meaning that accident pilots received a weather briefing but did not file a flight plan. Therefore such pilots were made aware of the weather but did not take the additional step of filing. Pilots who were communicating with ATC at the time of the crash were less likely to be involved in a VFR into IMC accident $(r=-.043)$ which seems to make sense as ATC could potentially assist the pilot get to VFR weather or away from hazardous terrain. Contrarily, non-VFR into IMC accidents are more likely to be in communication with ATC.

In agreement with the study by Goh and Wiegmann (2001), as pilot certification level went up, the likelihood of a VFR into IMC even went down $(r=-.641)$. Although it was surprising how many ATP pilots were involved is these types of accidents, it appears that, in general, the lower the certification, the higher the incidence of straying into marginal weather. This should not be surprising as the evaluation of weather does take experience and, in theory, pilots with high levels of certification have received more training and exposure to weather than pilots with those with lower certifications. Pilot flight time in hours is related to certification as each level requires higher amounts of experience, yet there was a positive correlation $(r=.535)$ meaning pilots involved in VFR into IMC accidents had more flight time. Coupled with the previous correlate, this indicates that pilots with lower certification with a higher number of hours were more likely to perform VFR into IMC. This could be due to a lack of training or professionalism associated with higher certificated pilots. This also can be due to the fact that pilots with more flight time have higher exposure levels to hazards, including unanticipated or 
disregarded poor weather. Lastly, pilots with higher flight time may feel more confident to take on weather that may exceed their expectations or abilities.

Age was found to be negatively correlated $(r=-.722)$ which indicates that younger pilots are more likely to conduct VFR into IMC. This agrees with the general premise of $\mathrm{Li}$, et al. (2001), which was that young pilots are more likely to commit errors. With age comes experience and it is not an unusual finding that pilots with less exposure to weather may not have yet grasped an understanding of how to predict or avoid dangerous conditions.

Partial correlations were conducted to gain insight into potential relationships while controlling for variables identified as significant within the original regression model. When controlling for terrain there were few insightful findings as the relationships of interest were similar to that predicted by the model. Contrary to the model, however, a positive correlation existed for flight plans $(r=.501, p<0.001)$ indicating that when controlling for terrain, pilots involved in VFR into IMC were more likely to file. Others findings were generally intuitive such as older pilots had more flight time, pilots with higher certification had more flight time, pilots who filed flight plans were more likely to be in contact with ATC. When controlling for weather briefings, terrain and pilot flight time showed a correlation of $r=.266(p<0.05)$ meaning accident pilots flying over mountain terrain had higher hours. A negative correlation $(r=-.247, p$ $<0.05)$ existed between terrain and flight plan meaning accident flights over mountainous terrain were less likely to be on a flight plan. The other findings agreed with the model or were intuitive as mentioned previously. 


\section{CONCLUSIONS}

Considering the high cost of aviation accidents, in particular, continued VFR into IMC types, research into the causes and factors of these events is critical to better understanding and potentially preventing them. This research aimed to identify pilot-related and situational factors that may be related to continued VFR into IMC accidents. The results of this study indicate a significantly accurate model of factors that are connected to these instances. The two factors showing the highest predictive capabilities were terrain and weather briefing. Since continued VFR into IMC was more likely to occur in mountainous areas it is logical to provide pilots with more training or experience in such areas especially since they are subject to rapidly changing or poor weather conditions. Particularly as the FAA has moved to situation based training (SBT), these findings could provide topics for training events or improving existing situational tasks.

Considering that pilots who were involved in continued VFR into IMC received a weather briefing, it points to the need to focus on weather education as well as hazardous pilot attitudes. Perhaps pilots are not heeding the warnings of weather briefers or sources either because they do not grasp the required knowledge to evaluate weather reports and factors. Also, they may feel as though they are invulnerable due to having made the flight before, overconfidence, or other negative attitudes. This too could provide basis for improving SBT scenarios and general pilot education. Moreover, weather briefer training could be modified or augmented to better provide pilots with warnings and hazards that may influence pilot decision making. Other findings such as that pilots with lower certification are more likely to be involved in these types of accidents indicates that improvements in weather education and SBT could be beneficial to neophyte pilots. Additionally, the fact that pilots with low certification level and 
high flight time having a higher incidence of VFR into IMC accidents beckons improved recurrent training to include SBT and hazardous attitude evaluation and/or training.

In sum, this study was able to confirm that factors identified in previous research and related to accident events were factors in the determination of accident type in terms of continued VFR into IMC or non-VFR into IMC. Further research is necessary to determine if other factors may be able to create a better model. Moreover, a replicative study using a larger sample size may provide more concrete evidence for a predictive model. Findings could continue to improve pilot education and training. 


\section{References}

Agresti, A. (2007). An introduction to categorical data analysis ( $2^{\text {nd }}$ ed.). Hoboken, NJ: Wiley.

AOPA. (2011). 22 $2^{\text {nd }}$ Nall report: Accident trends and factors for 2010. Fredericksburg, MD: Author.

AOPA. (2008). 2008 Nall report: Accident trends and factors for 2007. Fredericksburg, MD: Author.

AOPA. (2009). GA serves America: Learn more. Retrieved from http://www.gaservesamerica.com/learnmore.html

Air Transport Association. (2009). The importance of aviation to enabling economic recovery. Retrieved from http://www.airlines.org/news/speeches/news_05-08-09.htm

Billings, C. E., \& Reynard, W. D. (1984). Human factors in aircraft incidents: Results of a 7 year study. Aviation, Space, and Environmental Medicine, 55, 960-965.

Coyne, J. T. (2004). Crisp and fuzzy signal detection theory and pilot weather judgment: Implications for VFR flights into IMC. (Doctoral Dissertation). Available from ProQuest Dissertations and Theses database. (UMI Number 3160634).

Detwiler, C., Holcomb, L., Hackworth, C., \& Shappell, S. (2008). Understanding the human factors associated with visual flight rules flight into instrumental meteorological conditions. DOT/FAA/AM, 8/12. Washington, DC: DOT.

FAA. (2010). Accident \& incident data. Retrieved from http://www.faa.gov/data_research/accident_incident/

FAA. (2008). Instrument flying handbook. New York: Skyhorse Publishing.

Garland, D. J., Wise, J. A., \& Hopkin, V. D. (Eds.). (1999). Handbook of aviation human factors. New York: Psychology Press.

Goh, J., \& Wiegmann, D. (2001). An investigation of the factors that contribute to pilots' decisions to continue visual flight rules into adverse weather. Proceedings of the Human Factors and Ergonomics Society, Annual Meeting, 1, 26-29.

Helmreich, R. L. (1995). Critical issues in developing and evaluating CRM. In International Civil Aviation Organization (Ed.), Seminar manual - First regional human factors training seminar, Hong Kong, September 1995. Montreal, Canada: Author.

Helmreich, R. L., Wilhelm, J.A., Sherman, P., Gregorich, S., \& Wiener, E. (1993). The Flight Management Attitude Questionnaire (NASA/UT/FAA Technical Report No. 93-4). Austin, TX: NASA.

Hunter, D. R. (2001). Retrospective and prospective validity of aircraft accident risk indicators. Human Factors, 43(4), 509-519. 
Krause, S. (2003). Air safety: Accident investigations, analyses, \& applications $\left(2^{\text {nd }}\right.$ ed). New York: McGraw-Hill.

Landsberg, B. (2004). Why VFR into IMC? Retrieved from http://www.aopa.org/asf/asfarticles/2004/sp0401.html

Li, G., Baker, S., Grabowski, J., \& Rebok, G. (2001). Factors associated with pilot error in aviation crashes. Aviation, Space, and Environmental Medicine, 72(1), 52-58.

Li, G., Baker, S., Grabowski, J., Qiang, Y., \& Rebok, G. (2002). Age, flight experience and the risk of crash involvement in a cohort of professional pilots. Annals of Epidemiology, 12(7), 511.

Li, G., Baker, S., Lamb, M., Qiang, Y., \& McCarthy, M. (2005). Characteristics of alcohol related fatal general aviation crashes. Accident Analysis \& Prevention, 37(1), 143-148.

Merritt, A. C., \& Helmreich, R. L. (1995). Culture in the cockpit: A multi-airline study of pilot attitudes and values. In R. S. Jensen (Ed.), Proceedings of the Eighth International Symposium on Aviation Psychology. Columbus, OH: The Ohio State University.

NTSB. (2013a). Aviation accident statistics. Retrieved from http://www.ntsb.gov/data/table10_2012.html

NTSB. (2013b). Investigations. Retrieved from http://www.ntsb.gov/investigations/index.html

NTSB. (2002). Major investigations manual. Retrieved from http://www.ntsb.gov/Aviation/Manuals/MajorInvestigationsManual.pdf

NTSB. (n.d.). Reporting an accident to the NTSB. Retrieved from http://www.ntsb.gov/AVIATION/report.htm

O’Hare, D., \& Roscoe, S. (1990). Flight deck performance: The human factor. Ames, IA: Iowa State University Press.

Pallant, J. (2007). SPSS survival manual ( $3^{\text {rd }}$ ed.). Berkshire, UK: Open University Press.

Pearson, D. C. (2002). VFR flight not recommended: A study of weather-related fatal aviation accidents. Retrieved from http://www.srh.noaa.gov/topics/attach/html/ssd02-18.htm

Roscoe, S. N. (1980). Aviation psychology. Ames, IA: Iowa State University Press.

Salas, E., Fowlkes, J., Stout, R., Milanovich, D., \& Prince, C. (1999). Does CRM Training Improve Teamwork Skills in the Cockpit?: Two Evaluation Studies. Human Factors: The Journal of the Human Factors and Ergonomics Society, Vol. 41(2), 326-343.

Transport Canada. (2011). Air annual statistics. Retrieved from http://www.bsttsb.gc.ca/eng/stats/aviation/prelim-2011/ 
Wiegmann, D. A., Goh, J., \& O'Hare, D. (2002). The role of situation assessment and flight experience in pilots' decisions to continue visual flight rules flight into adverse weather. Human Factors: The Journal of the Human Factors and Ergonomics Society, 44(2), 189197.

Wiegmann, D. A. \& Shappell, S. A. (2003). A human error approach to aviation accident analysis: The human factors analysis and classification system. Hants, England: Ashgate Publishing Limited.

Wiener, E. L., Kanki, B. G., \& Helmreich, R. L. (Eds.). (1993). Cockpit resource management. San Diego, CA: Academic Press. 